\title{
INDICAÇÃO DE USO E OCUPAÇÃO DO SOLO DA COMUNIDADE QUILOMBOLA BARRA DO AROEIRA - SANTA TEREZA DO TOCANTINS - TO
}

\section{Indication of use and soil occupancy of the quilombola community Barra do Aroeira - Santa Tereza do Tocantins - TO}

\author{
Michele Ribeiro Ramos \\ Universidade Estadual do Tocantins \\ michele.rr@unitins.br \\ Matheus Borges do Amorim \\ Universidade Estadual do Tocantins \\ m.borges695@gmail.com \\ Olivia de Campos Maia Pereira \\ Universidade Federal do Tocantins \\ oliviamaia@uft.edu.br \\ Andressa Caroline Silva Leitão Gomes \\ Universidade Federal do Tocantins \\ andressacslg@hotmail.com
}

\begin{abstract}
RESUMO: O uso do solo deve ser planejado antes de qualquer intervenção em áreas agrícolas e/ou urbanas e a avaliação das características do solo é um fator chave para a tomada de decisão. Para colocá-lo em prática, foi realizado o diagnóstico territorial da comunidade quilombola "Barra da Aroeira", localizada no município de Santa Tereza do Tocantins - TO, para avaliar o uso do solo por meio dos critérios de capacidade de uso e aptidão agrícola do sistema. Anteriormente, era realizado um levantamento de solo para definir a distribuição das classes de solo e permitir uma melhor compreensão da ocupação do solo. O mapeamento do solo foi realizado em escala semi-detalhada e as trincheiras foram distribuídas por toda a área pesquisada. Em cada trincheira, os horizontes foram identificados, descritos e amostras deformadas foram coletadas para análises químicas e granulométricas. Além disso, amostras indeformadas (utilizando anéis de Kopecky) foram coletadas, quando possível, para um levantamento físico-hídrico. Após a análise dos dados pedológicos, hipsométricos e climáticos/vegetacionais, foi realizada a sistematização. Cinco classes de solo foram encontradas na área de estudo, a saber: Plintossolos, Neossolos, Cambissolos, Gleissolos e Latossolos. Os mapas de capacidade de uso e aptidão agrícola foram elaborados considerando as necessidades de produção dos moradores em termos de lavouras, bem como as potencialidades e limitações dos solos da área, visando propostas de uso sustentável. Foi diagnosticado que a maior parte da área não apresentava boas condições de uso agrícola, além de alto potencial erosivo, com base nas condições naturais da região e na capacidade orçamentária dos moradores.
\end{abstract}

Palavras-chave: Uso e manejo; Potencialidades; Aptidão agrícola; Capacidade de uso.

ABSTRACT: Land use must be planned prior to any intervention in agricultural and/or urban areas and the evaluation of soil characteristics is a key factor for decision making. To put it into practice, the territorial diagnosis of the maroon community called "Barra da Aroeira", located at the municipality of Santa Tereza do Tocantins - TO, was made to assess the soil use by means of land use capacity and agricultural aptitude system criteria. A soil survey was formerly conducted to set soil classes distribution and allow a better comprehension of land occupancy. Soil mapping was performed on a semi-detailed scale and trenches were distributed all over the surveyed area. In each trench, the horizons were identified, described, and deformed samples were collected for chemical and 
INDICAÇÃO DE USO E OCUPAÇÃO DO SOLO DA COMUNIDADE QUILOMBOLA BARRA DO AROEIRA - SANTA TEREZA DO TOCANTINS - TO

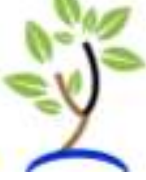

granulometric analysis. Also, undeformed samples (by using Kopecky rings) were collected, when possible, for a physic-hydric survey. After analyzing the pedological, hypsometric, and climate/vegetation data, systematization was carried out. Five soil classes were found in the study area, as follows: Plintossolos, Neossolos, Cambisolos, Gleissolos, and Latossolos. The maps of use capacity and agricultural aptitude were elaborated considering the production needs of the locals in terms of crops, as well as the potential and limitations of the soils of the area, aiming at proposals of sustainable use. It was diagnosed that most of the area did not have good conditions for agricultural use, as well as a high potential for erosion, based on the natural conditions of the region and the budget capacity of the residents.

Keywords: Land use and management; Potential and agricultural aptitude; Land use capacity.

\section{INTRODUÇÃO}

O planejamento do uso e ocupação de uma área é de fundamental importância para determinar a sobrevivência de uma população seja qual ela for. Nesse contexto, levantamento e classificação dos solos podem contribuir na escolha de técnicas de uso e manejo sustentável do solo.

A história da formação da nação brasileira resultou em diversas relações sociais evidenciadas por processos de resistência e opressão. Ocorre que ao longo desse processo de formação (uso e ocupação) do território brasileiro pelos negros instrumentos legais, ao final da década de 80 , viabilizaram o direito a cidadania, proteção estatal, patrimônio materiais, garantindo às comunidades negras rurais que provarem sua origem quilombola, o direito a ter seus territórios (MARIN; ALMEIDA, 2006). Essas comunidades vivem praticamente da agricultura familiar, sem uso de tecnologias e na maioria das vezes em áreas marginalizadas desprovidas de qualidade, em relevos íngremes e solos de baixa fertilidade. Estima-se que exista mais de duas mil e seiscentas comunidades quilombolas no Brasil (FCP, 2016), um número bem expressivo.

No entanto, seus territórios sofrem pressão e estão permanentemente ameaçados pela expropriação de suas terras, devido principalmente à falta de políticas públicas, assistência técnica, recursos para viabilizarem suas produções, e, sobretudo pela não ocupação de seus territórios de forma efetiva devido a esses fatores já mencionados (PINTO et al., 2014). Desta forma, o uso de seus territórios deve ser feito com planejamento adequando as condições do meio físico ao nível tecnológico adotado por eles, evitando o uso do solo acima da sua capacidade produtiva, adotando práticas conservacionistas e agroecológicas para suas produções (ALTIRE et al., 2012; NIERDELE et al., 2013).

Com base nisso, no município de Santa Tereza do Tocantins, a comunidade Barra do Aroeira através de meios legais, constituiu uma área para construção de suas habitações e exercer atividades agrícolas. Porém, a ocupação do território quilombola não é feita em lotes individuais, pois o convívio e o uso são comuns a todos, onde todas as atividades agrícolas ou não agrícolas reúnem-se em um mesmo espaço ocupado por essas famílias. Essas diferentes formas de uso e ocupação coloca em risco a qualidade ambiental da área, põe em risco a qualidade do solo e da água e principalmente a saúde dos habitantes desta comunidade. 
INDICAÇÃO DE USO E OCUPAÇÃO DO SOLO DA COMUNIDADE QUILOMBOLA BARRA DO AROEIRA - SANTA TEREZA DO TOCANTINS - TO

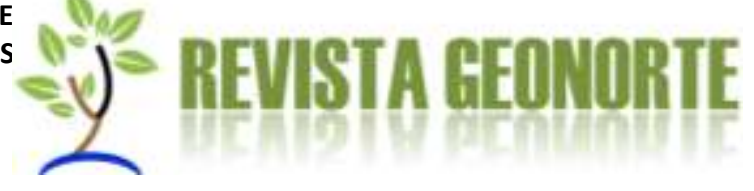

Para evitar um colapso da qualidade do solo e água e consequentemente o adoecimento da população, o planejamento do uso e ocupação desse território se torna primordial. Além das definições quanto a capacidade de uso e a aptidão agrícola desses solos, identificar os usos causadores de menores distúrbios no ambiente, reutilizar ou fazer a disposição final de resíduos produzidos a fim de garantir qualidade ambiental para essa comunidade.

Estudar os solos irá garantir harmonia entre o homem e a natureza, associando produção ao desenvolvimento sustentável. Certas características devem ser observadas, como por exemplo, a profundidade efetiva do solo, o teor de argila, se este apresenta alguma camada de impedimento (horizonte adensado, fragipans, duripans), além de outras características como declividade e comprimento de rampa. Outro fator é a capacidade de suporte que cada solo tem, ou seja, são mais resilientes ou não a um determinado uso específico. Todo esse conjunto de informações são necessárias para avaliar a qualidade do solo. Conhecer esses fatores é crucial para estabelecer o bom funcionamento de um ecossistema, de uma bacia hidrográfica.

O presente trabalho avaliou a capacidade de uso e a aptidão agrícola dos solos da comunidade de Quilombo Barra do Aroeira, localizado no município Santa Tereza TO, por meio da sistematização de informações provenientes das análises de solo, dados georreferenciados, para subsidiar tomadas de decisões sobre o uso e ocupação do território.

\section{MATERIAIS E MÉTODOS}

O mapeamento temático dos compartimentos do meio físico da Bacia Hidrográfica do Rio das Balsas foram geoprocessados utilizando o software QGIS, versão 3.8 e a base de dados geográficas do ano de 2012 da Secretaria da Fazenda e Planejamento do Estado do Tocantins.

Para esta configuração, considerou-se a área de influência direta (AID) todo o perímetro do território quilombola, onde foram realizadas as coletas de solo, e sequencialmente as análises laboratoriais, e, a bacia hidrográfica do Rio das Balsas como área de influência indireta (AII), o qual a comunidade está inserida conforme mostra o mapa de Localização (Figura 1). 
INDICAÇÃO DE USO E OCUPAÇÃO DO SOLO DA COMUNIDADE QUILOMBOLA BARRA DO AROEIRA - SANTA TEREZA DO TOCANTINS - TO
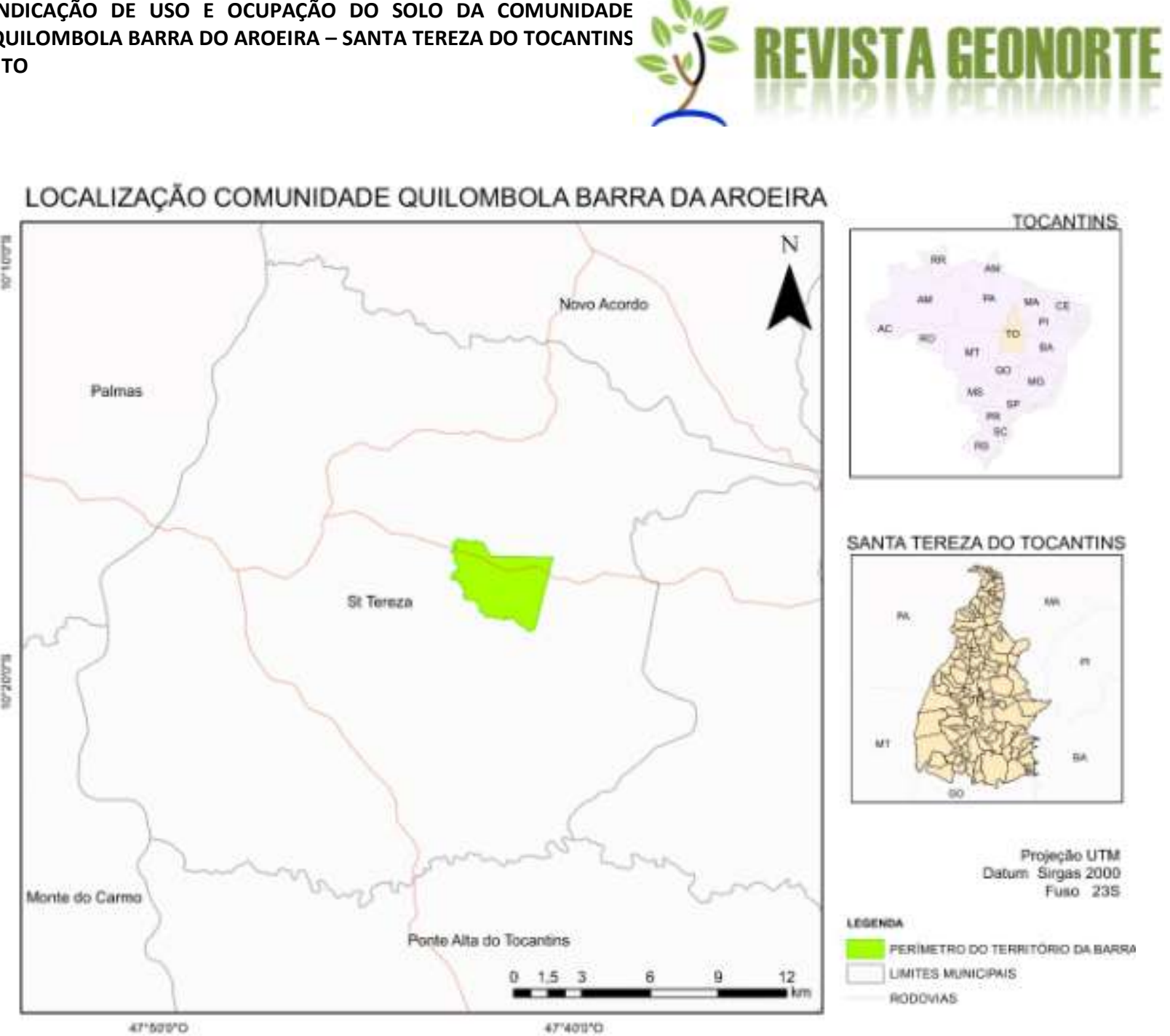

Figura 1 - Mapa de localização da comunidade Quilombola Barra do Aroeira - Santa Tereza do Tocantins - TO

Foi realizada uma prospecção na área a fim de identificar áreas homogêneas, e elaboração do mapa de solos, que serviu de base para os estudos posteriores. O método utilizado foi o de Topossequência (EMBRAPA, 1995) associado ao caminhamento livre. Em cada área foi aberto uma trincheira de até $2,0 \mathrm{~m}$ de profundidade e as informações foram complementadas com a coleta de amostras complementares e observações, resultando em um levantamento semidetalhado na área (0,2 a 4 amostras/ha).

Em cada trincheira foram identificados os horizontes e coletadas amostras deformadas, para análise química e granulométrica, e indeformadas (anéis de kopecky), para estudo físico-hídrico, para posteriormente serem classificados de acordo com Embrapa (2018). As amostras complementares foram coletadas com o auxílio do trado holandês, para caracterização química e granulométrica dos pontos amostrados.

As amostras foram levadas para o Laboratório onde foram secas ao ar e posteriormente passadas em peneiras de $2 \mathrm{~mm}$, para a obtenção da terra fina. Posteriormente, foram submetidas às análises químicas ( $\mathrm{Ca}, \mathrm{Mg}, \mathrm{K}, \mathrm{P}, \mathrm{V} \%, \mathrm{~m} \%$, CTC, pH em água) e de granulometria (areia, silte e argila). $\mathrm{O} \mathrm{pH}$ do solo, a acidez 
INDICAÇÃO DE USO E OCUPAÇÃO DO SOLO DA COMUNIDADE QUILOMBOLA BARRA DO AROEIRA - SANTA TEREZA DO TOCANTINS - TO

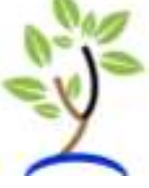

trocável $\left(\mathrm{Al}^{+3}\right)$, os teores de $\mathrm{P}, \mathrm{K}+\mathrm{Ca}$ e $\mathrm{Mg}$ trocáveis, acidez potencial $\left(\mathrm{H}^{+}+\mathrm{Al}^{+}\right)$, matéria orgânica saturada (M.O.S) e carbono orgânico (C) foram determinadas de acordo com metodologia apresentada pela EMBRAPA (2017). A partir dos valores de acidez potencial, bases trocáveis e alumínio trocável, foram calculados a soma de bases (SB), a capacidade de troca de cátions (CTC), a porcentagem de saturação por bases (V\%) e a porcentagem de saturação por alumínio (m\%).

Por fim, foram coletadas amostras indeformadas de solo (anel metálico - Kopecky) com volume de $73,44 \mathrm{~cm}^{-3}$, sendo 03 amostras no primeiro horizonte de cada trincheira e duas amostras nos demais horizontes do perfil. Após a coleta, as amostras foram encaminhadas para o laboratório, para a realização das seguintes análises: condutividade hidráulica, densidade do solo e porosidade total de acordo com a metodologia detalhada em Embrapa (2017).

Para a sistematização da área foi utilizado o sistema de capacidade de uso da terra (LEPSCH et al.,1991), com intuito de identificar as limitações permanentes e os possíveis usos das terras. Esse sistema avalia as características do meio físico a fim de definir a máxima capacidade de uso, evitando riscos de degradação. Por ser um sistema desenvolvido pelo Serviço Nacional de Conservação do Solo (NRCS-USDA) na década de 1930, ele agrupa qualitativamente as classes de solos sem considerar características econômicas, isso se deve porque a condição econômica dos proprietários de terras é considerada relativamente alta as condições no Brasil.

Devido a essa característica, vê-se a necessidade de sistematizar os solos também de acordo com o Sistema de Aptidão Agrícola do solo que considera 06 grupos de aptidão, para avaliar as condições agrícolas de cada unidade de mapeamento, não só para lavouras, mas também para pastagens plantadas, silvicultura e pastagem natural, sendo as áreas inaptas para estes tipos de utilização, devem ser destinadas para a preservação. Além disso, o sistema avalia as condições socioeconômicas do produtor em três níveis de manejos distintos, tendo em vista práticas agrícolas ao alcance da maioria dos agricultores, visando diagnosticar o comportamento das terras em diferentes níveis tecnológicos. Idealizado por Bennema et al., (1965), sofreu várias alterações até chegar na versão que atualmente é utilizada descrita por Ramalho-Filho; Beek (1995).

\section{RESULTADOS E DISCUSSÕES}

As características químicas dos solos estudados estão apresentadas na Tabela 1. Pode-se observar que todos os solos são dessaturados por bases, com exceção do Latossolo Eutrófico, situado dentro uma propriedade, essa área é manejada com adubos e calcário, e por essa razão os valores de saturação por bases são elevados, implicando em saturação de alumínio nula. Os demais solos esse índice apresentou-se bastante elevado, indicando a necessidade de fazer a correção.

Tabela 1 - Características químicas e granulométricas dos solos dos respectivos perfis estudados. 
INDICAÇÃO DE USO E OCUPAÇÃO DO SOLO DA COMUNIDADE QUILOMBOLA BARRA DO AROEIRA - SANTA TEREZA DO TOCANTINS - TO

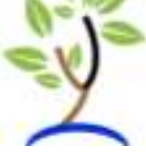

\begin{tabular}{|c|c|c|c|c|c|c|c|c|c|c|c|c|c|}
\hline \multicolumn{14}{|c|}{ PERFIS } \\
\hline \multirow{2}{*}{ riz } & A & Silte & moia & $\mathbf{P}$ & $\mathbf{K}$ & $\mathbf{V}$ & $\mathbf{m}$ & M.O. & $\sigma$ & $\mathbf{C a}$ & Mg & Al & \multirow{2}{*}{$\begin{array}{c}\mathrm{pH} \\
(\mathrm{CaCl} 2)\end{array}$} \\
\hline & \multicolumn{3}{|c|}{ Teores \% } & \multicolumn{2}{|c|}{$\mathrm{mg} / \mathrm{dm}^{3}$} & \multicolumn{3}{|c|}{$\%$} & \multicolumn{4}{|c|}{$\mathrm{cmolc} / \mathrm{dm}^{3}$} & \\
\hline \multicolumn{14}{|c|}{ CAMBISSOLO FLÚVICO Tb Distrófico gleissólico A proeminente textura argilosa } \\
\hline A & 150 & 48,50 & 7,00 & 159 & 72,00 & 17,45 & 0 & 202 & 16,96 & 1,48 & 1,04 & 1,86 & \\
\hline DI & 40,00 & 40,50 & 4,30 & $1, T 1$ & J & $4, \mathrm{C}$ & & & & 0,21 & 0,14 & 2,00 & \\
\hline B2 & 50,80 & 46,70 & 2,50 & 10,20 & 9 & 3,0 & 88 & 1,53 & 10,31 & 0,06 & 0,15 & 2,29 & 97 \\
\hline $\mathrm{Bg}$ & 4 & 51,70 & 2,40 & 20,65 & 39,09 & 3,14 & 86,35 & 2,22 & 10,84 & 0,13 & 0,11 & 2,15 & \\
\hline \multicolumn{14}{|c|}{ LATOSSOLO AMARELO Eutrófico argissólico A moderado textura argilosa } \\
\hline A & 23,20 & 17,30 & 59,50 & 127,99 & 129,00 & 64,94 & 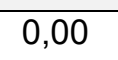 & & 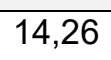 & 8,22 & 7 71 & $\overline{0,}$ & D,U \\
\hline$A B$ & 18,90 & 18,20 & 62,90 & 32,78 & 42,90 & 61,07 & 0,00 & 1, & 8,22 & 4,65 & 0,26 & 0,00 & 5 \\
\hline BA & 26,50 & 27,00 & 46,50 & 16,84 & 19,55 & 53,54 & 0,00 & 0,5 & 4,95 & 2,38 & 0,22 & 0,00 & 0 \\
\hline B1 & 32,40 & 19,10 & 48,50 & 5,29 & 15,64 & 57,18 & 0,00 & $0, \cup$ & ( & 1,97 & 0,26 & 0 , & \\
\hline \multicolumn{14}{|c|}{ NEOSSOLO REGOLÍTICO Distrófico fragipã A moderado textura argilosa } \\
\hline A & 30,80 & 32,40 & 36,80 & 1,39 & 4,73 & 10, & 5 & & 10, & 0,67 & 0,3 & $\overline{1,2}$ & 3,20 \\
\hline C & 19,00 & 36,00 & 45,00 & 0,22 & 3,91 & 6,67 & 78,45 & 0,51 & 3,75 & 0,19 & 0,05 & 0,9 & 3,80 \\
\hline \multicolumn{14}{|c|}{ NEOSSOLO REGOLÍTICO Distrófico fragipã A moderado textura média siltosa } \\
\hline A & 16,90 & 56,30 & 26,80 & 0,22 & 13,36 & 21,95 & & 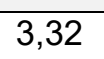 & 10,25 & 0,97 & 0,99 & 0,65 &, 09 \\
\hline C & 52,60 & 39,20 & 8,20 & 0,30 & 54,73 & 19,79 & 51,95 & 0,22 & 9,35 & 0,17 & 1,54 & 2,00 & $3, \varepsilon$ \\
\hline \multicolumn{14}{|c|}{ AMBISSOLO HÁPLICO Ta Distrófico leptofragmentário A moderado textura franco-argil } \\
\hline$A$ & 5 & 0 & 7,80 & 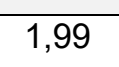 & & & & & & 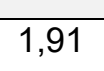 & $\bar{T}$ & & \\
\hline$B C$ & 3 & 30, & 2 & U & 9 & 1 & 3 & 1 & 9,37 & 6 & 9 & U & 4,12 \\
\hline C & 41,10 & 35,20 & 23,70 & 0,62 & 89,91 & 8,75 & 69,60 & 0,64 & 7,89 & 0,19 & 0,27 & 1,58 & \\
\hline \multicolumn{14}{|c|}{ PLINTOSSOLO PÉTRICO Concrecionário típico A moderado textura franc } \\
\hline A & 0 & 7,30 & 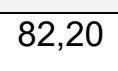 & 15,40 & & 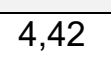 & & & 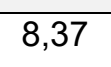 & 0,19 & 0,09 & 0,76 & 4,09 \\
\hline$A B$ & 11,20 & 7,10 & 81,70 & 0 , & r & 1 & 2 & 2 & 5 & 0,03 & 0,01 & 0,33 & 4,14 \\
\hline Bf1 & 12,50 & 8,50 & 79,00 & 0,22 & 7,82 & 0,99 & 32 & 1,86 & 4,04 & 0,01 & 0,01 & 0,18 & 4,21 \\
\hline Bf2 & 14,30 & 11,30 & 74,40 & 0,22 & 35,18 & 4,11 & 25,00 & 1,05 & 3,65 & 0,04 & 0,02 & 0,05 & 4,56 \\
\hline \multicolumn{14}{|c|}{ PLINTOSSOLO PÉTRICO Concrecionário típico A moderado textura franco-arenosa } \\
\hline A & 10,50 & 5,90 & 83,60 & 2,19 & & 4,06 & 52,17 & 2 & 5,42 & 0,14 & 0,03 & 0,24 & 3,88 \\
\hline $\mathrm{Bf} 1$ & 10,20 & 11,90 & 77,90 & 0,42 & 11,73 & 2,08 & 72,00 & 1,09 & 3,37 & 0,03 & 0,01 & 0,18 & 4,08 \\
\hline $\mathrm{Bf} 2$ & 22,50 & 16,20 & 61,30 & 0,22 & 3,91 & 4,46 & 30,00 & 0,84 & 3,14 & 0,11 & 0,02 & 0,06 & 4,32 \\
\hline
\end{tabular}

Em contrapartida a capacidade de troca catiônica apresentou índices baixos para todos os solos avaliados, independente do horizonte. Os valores de $\mathrm{pH}$ também foram baixos, sendo apenas na área cultivada Latossolo Eutrófico, em uma faixa acima de 5.

REVISTA GEONORTE, V.12, N.40, p.24-40, 2021.

DOI: 10.21170/geonorte.2021.V.12.N.40.24.40

(ISSN 2237 - 1419) 
INDICAÇÃO DE USO E OCUPAÇÃO DO SOLO DA COMUNIDADE QUILOMBOLA BARRA DO AROEIRA - SANTA TEREZA DO TOCANTINS - TO

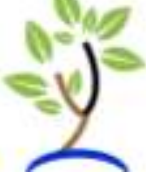

Com relação aos teores de K nos solos do cerrado Sousa e Lobato (2004) descrevem que para solos com CTC potencial superiores a $04 \mathrm{cmolc} / \mathrm{dm}^{3}$, os teores de $\mathrm{K}$ menores que $25 \mathrm{mg} / \mathrm{kg}$ são considerados baixos e teores entre 51 a $80 \mathrm{mg} / \mathrm{kg}$ são considerados adequados e valores superiores a $80 \mathrm{mg} / \mathrm{kg}$ são classificados como teores alto de K. Desta forma, podemos verificar que os Cambissolos Flúvicos, Latossolo Amarelo, Neossolo Regolítico textura siltosa, Cambissolo Háplico estão com teores de potássio considerados altos. Já os Neossolo Regolítico textura argilosa, os teores estão dentro da faixa adequada, e finalmente para os Plintossolo Pétricos tanto para o solo de textura franco e franco argilosa esses são considerados médio.

Em contrapartida os valores de $\mathrm{P}$ (fósforo) para solos de textura argilosa, são considerados, teores maiores que $6 \mathrm{mg}^{\mathrm{dm}} \mathrm{dm}^{-3}$ já são ditos altos, e para os de textura leve acima de $25 \mathrm{mg} \cdot \mathrm{dm}^{-3}$, (SOUSA; LOBATO, 2004). Desta forma, só o Latossolo Eutrófico apresentou valores muito acima deste limite, em contrapartida, os demais estão com teores considerados muito baixo.

A matéria orgânica foi maior que $5 \%$ no horizonte $A$, apenas para o Cambissolo Háplico, onde o uso era pastagem e cerrado em regeneração. É sabido que as gramíneas utilizadas como forrageiras tendem a desenvolver a estrutura do solo, aumentar a atividade microbiana e por consequência incrementar a matéria orgânica do solo, além do aporte com entrada dos resíduos produzidos pelos animais. Outra situação, onde os teores ficaram inferiores, porém próximos destes, foi no Plintossolo Pétrico cultivado com feijão $(4,6 \%)$, trata-se de uma área recém-aberta, onde os produtores estavam iniciando os cultivos com leguminosas, que apesar da estrutura fraca do solo e textura franca/arenosa, apresentava valores significativos de matéria orgânica.

Contudo, sabemos que com o passar dos anos de cultivos essa é uma área que está designada a passar por processo de degradação, se não forem tomadas atitudes que envolvam práticas conservacionistas. O outro Plintossolo Pétrico sob cerrado, os teores não foram altos $(2,3 \%)$.

Em relação à textura, apenas os Cambissolos e os Latossolos apresentaram textura médio-argilosa, os demais foram classificados com arenosos e francos. Essa característica é bastante importante, pois reflete não apenas restrições a fertilidade química, como também problemas relacionados à qualidade estrutural desses solos e por consequência, formação de processos erosivos, principalmente quando associados a relevos ondulados, como é o caso desses.

Sobre as características físico-hídricas verifica-se que as densidades dos solos dos perfis que foram possível coletar, devido a presença de cascalho e calhaus originado da decomposição das rochas nos Neossolos e da presença de nódulos/concreções originadas do endurecimento das plintitas nos Plintossolos, pode-se observar que com exceção do Cambissolo gleissólico que tiveram densidades constantes e baixas ao longo do perfil, nas demais classes esses valores chegaram ao horizonte $A$ até $1,49 \mathrm{~g} \mathrm{dm}^{-3}$, e nos horizontes de subsuperfície até $1,73 \mathrm{~g} \mathrm{dm}^{-3}$ (Figura 2). E no Plintossolo Pétrico que foi possível coletar, encontrou-se no horizonte $A 1,39 \mathrm{~g} \cdot \mathrm{dm}^{-3}$, 
INDICAÇÃO DE USO E OCUPAÇÃO DO SOLO DA COMUNIDADE QUILOMBOLA BARRA DO AROEIRA - SANTA TEREZA DO TOCANTINS - TO

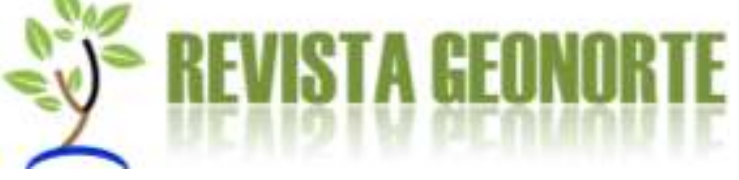

valor semelhante as outras classes, porém nos horizontes subsuperficiais valores que atingiram $1,95 \mathrm{~g} \mathrm{dm}^{-3}$.
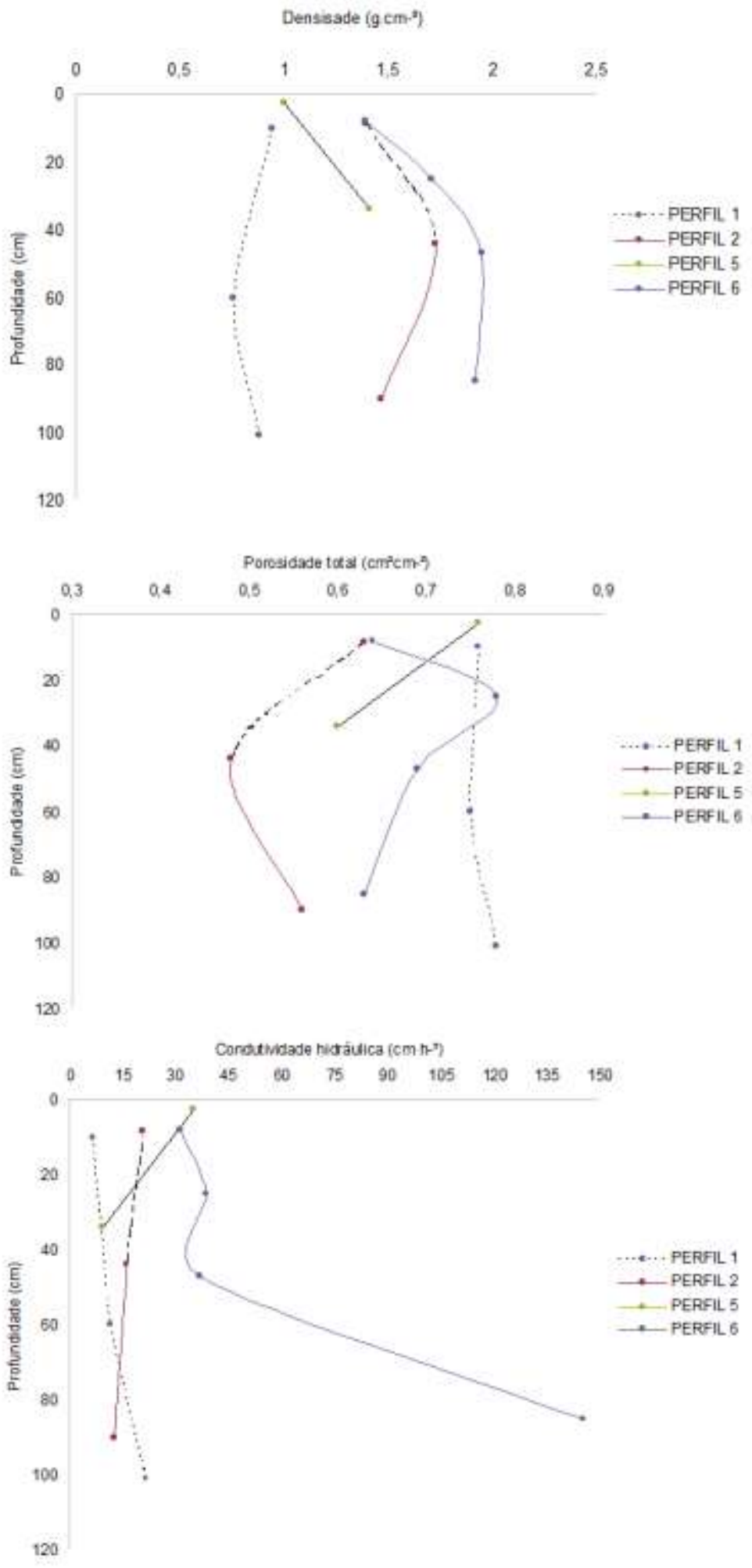
INDICAÇÃO DE USO E OCUPAÇÃO DO SOLO DA COMUNIDADE QUILOMBOLA BARRA DO AROEIRA - SANTA TEREZA DO TOCANTINS - TO
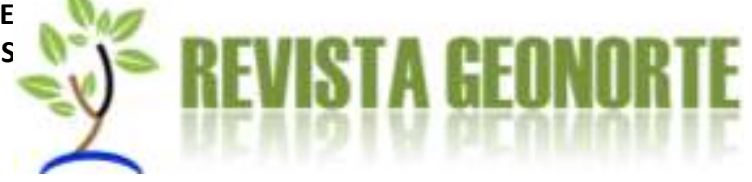

Figura 2 - Propriedades físicas dos solos da Comunidade Barra do Aroeira - Santa Tereza do Tocantins - TO. Perfil 1: CAMBISSOLO FLÚVICO Tb Distrófico gleissólico Perfil 2: LATOSSOLO AMARELO Eutrófico argissólico Perfil 5: CAMBISSOLO HÁPLICO Ta Distrófico leptofragmentário Perfil 6: PLINTOSSOLO PÉTRICO Concrecionário típico

Esse resultado pode ser justificado pela presença de petroplintita nesses horizontes, que contribuiu com esse aumento demasiado da densidade nessas camadas. Essa limitação é comum nos Plintossolos Pétricos e foi verificada por França et al, (2019), na mesma classe de solo indicada, sendo essa restrição prejudicial na sistematização da área para indicação agrícola.

Em contrapartida, a porosidade total foi constante ao longo do perfil em todas as classes de solo, acima de $50 \mathrm{~cm}^{3} . \mathrm{cm}^{-3}$. Esse parâmetro de forma subjetiva indica que os solos apresentam boas condições de aeração e armazenamento de água.

A condutividade hidráulica, que indica a velocidade de infiltração de água do solo, apresentou grandes variações, principalmente dentro do mesmo perfil, sugerindo um possível desajuste no fluxo hídrico dentro do solo. Onde se tem valores elevados em superfície e em subsuperfície valores baixos. Essa característica nos dá indícios de erosão de fluxos de subsuperfícies nessas áreas. O Cambissolo Háplico (perfil 5), é o exemplo dessa situação, $35,1 \mathrm{~cm} \cdot \mathrm{h}^{-1}$. Sendo ideal a condição estabelecida no Plintossolo Pétrico (perfil 6) onde os valores são contínuos, favorecendo a entrada da água de forma homogênea dentro do perfil.

A qualidade estrutural do solo como pode ser observado na Tabela 2, indica solos com estruturas bastante fraca, seja pelos baixos teores de matéria orgânica, já discutidos anteriormente, ou pelo uso intensivo dessas áreas sem uma base agroecológica que preconize o uso de práticas conservacionistas, que ajuda a minimizar os processos erosivos.

A presença de concreções ferruginosas, fragmentos de rochas em decomposição nas frações cascalhos e calhaus tornam a maioria desses solos inaptos ou aptos com algum tipo de restrição de uso agrícola. Pois além de diminuir o volume de terra fina, que corresponde a fração reativa do solo, muitos deles são extremamente rasos, apresentando camadas de impedimentos para o desenvolvimento de raízes e armazenamento de água, com é o caso dos Neossolos Regolíticos onde a profundidade efetiva não ultrapassa os primeiros $50 \mathrm{~cm}$.

Tabela 2 - Características físicas dos perfis, textura, qualidade estrutural, matriz de cor e consistência.

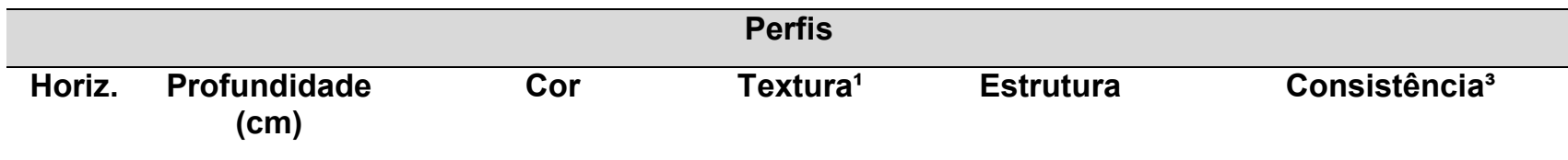

Perfil 1: CAMBISSOLO FLÚVICO Tb Distrófico gleissólico A proeminente textura argilosa

$\begin{array}{llllll}\text { A } & 0-20 & \text { 5YR 5/1 } & \text { FA } & \text { M; MP; GR } & \text { CD2; CM2; CP2; CS3 }\end{array}$


INDICAÇÃO DE USO E OCUPAÇÃO DO SOLO DA COMUNIDADE QUILOMBOLA BARRA DO AROEIRA - SANTA TEREZA DO TOCANTINS - TO

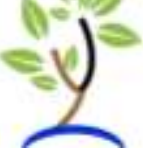

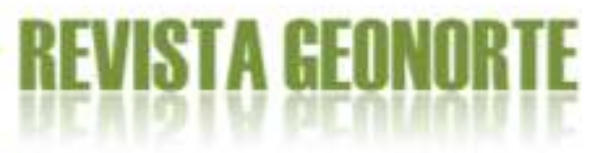

\begin{tabular}{lccccc} 
B1 & $20-80$ & $2,5 Y R 3 / 3$ & FA & M; PQ; AG/SAG & CD2; CM1; CP2; CS3 \\
B2 & $80-121$ & $5 Y R 4 / 4$ & FA & M; MD; AG/SAG & CD2; CM2; CP3; CS2 \\
Bg & $121-132+$ & 5 YR 3/1, 4/1 & FA & M; GD; AG & CD2; CM2; CP3; CS2 \\
\hline
\end{tabular}

Perfil 2: LATOSSOLO AMARELO Eutrófico argissólico A textura argilosa

\begin{tabular}{cccccc}
\hline A & $0-17$ & $5 Y R ~ 3 / 1$ & FR & M; MD/GD; AG & CD2; CM2; CP2; CS2 \\
AB & $17-29$ & $5 Y R 4 / 2$ & FR & M; PQ; AG & CD2; CM2; CP2; CS2 \\
BA & $29-60$ & $5 Y R 4 / 6$ & FR & FT; MD; SAG/AG & CD2; CM2; CP2; CS2 \\
B1 & $60-122+$ & $5 Y R 4 / 6$ & FR & M; MD; SAG/AG & CD2; CM1; CP3; CS2 \\
\hline
\end{tabular}

Perfil 3: NEOSSOLO REGOLÍTICO Distrófico fragipã

\begin{tabular}{cccccc}
\hline A & $0-46$ & $2,5 Y R$ 5/1 & FR & FC/M; PQ; AG & CP1; CS1 \\
C & $46-185+$ & $2,5 Y R ~ 5 / 6,8 / 1$ & FR & Maciça & Maciça \\
\hline \multicolumn{7}{c}{ Perfil 4: NEOSSOLO REGOLíTICO Distrófico fragipã } \\
\hline A & $0-50$ & $5 Y R$ 6/1 & FR & FC; ST; CC & CP1; CS1 \\
C & $50+$ & $5 Y R 6 / 8$ & FR & & \\
\hline
\end{tabular}

Perfil 5: CAMBISSOLO HÁPLICO Ta Distrófico leptofragmentário

\begin{tabular}{cccccc}
\hline A & $0-5(12)$ & $5 Y R 6 / 1$ & FA & M/FC; PQ/MD; & CD2; CP1; CS1 \\
BiC & $5-58$ & $7,5 Y R 6 / 3,6 / 4$ & FA & M/FC; GD/MD; AG & CD3; CP1; CS1 \\
C & $58-126+$ & $7,5 Y R 6 / 4$ & FA & Presença MO & \\
\hline
\end{tabular}

\begin{tabular}{cccccc}
\hline \multicolumn{5}{c}{ Perfil 6: PLINTOSSOLO PÉTRICO Concrecionário típico } \\
\hline A & $0-16$ & 5YR 2,5/2 & AR & M; MP; GR & CD1; CM1; CP4; CS4 \\
AB & $16-34$ & $5 Y R ~ 4 / 3$ & AR & MD; SAG/AG & CD1; CM1; CP4; CS4 \\
Bf1 & $34-60$ & 5YR 4/4 & FR & ST; GR & CP1; CS1 \\
Bf2 & $60-110+$ & 2,5 YR 4/6 & FR & FC; MP; GR & CM1; CP1; CS1 \\
\hline \multicolumn{5}{c}{ Perfil 7: PLINTOSSOLO PÉTRICO Concrecionário típico } \\
A & $0-19$ & 5YR 4/4 & AR & FC; PQ; AG & CD1; CM1; CP1; CS1 \\
Bf1 & $19-55$ & 5YR 4/6 & AR & FC; MP; GR; ST & CP2; CS1 \\
Bf2 & $55-132+$ & 2,5YR 4/8 & FR & FC; MP; GR; ST & CP2; CS1
\end{tabular}

${ }^{1}$ Textura: FR - franca, FA - franco-argilosa, AR - arenosa; ${ }^{2}$ Consistência: Quando úmido (CM1 muito friável, CM2 - friável); Quando seco (CD1 - macio, CD2 - ligeiramente duro, CD3 - duro); Plasticidade (CP1 - ligeiramente plástico, CP2 - plástico, CP3 muito plástico, CP4 não plástico); Consistência/Pegajosidade (CS1 - ligeiramente pegajoso, CS2 - pegajoso, CS3 muito pegajoso, CS4 não pegajoso); Estrutura ( $F T$ forte, $M$ moderada, $F C$ fraca, $M D$ média, $G D$ grande $P Q$ pequena, $M P$ muito pequena, GR Granular, AG angulares, SAG subangulares, ST solta, CC cascalhenta, MO material de origem)

Sobre a distribuição dos solos dentro da área, podemos considerar que de acordo com o Sistema Brasileiro de Classificação de Solos (EMBRAPA, 2018) foram encontradas e descritas cinco classes, sendo essas o Plintossolos, o Neossolos, o 
INDICAÇÃO DE USO E OCUPAÇÃO DO SOLO DA COMUNIDADE QUILOMBOLA BARRA DO AROEIRA - SANTA TEREZA DO TOCANTINS - TO

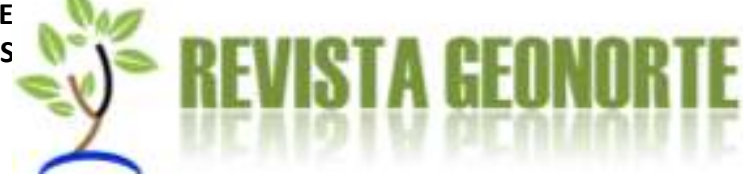

Cambissolos, o Gleissolos e o Latossolos, com as proporções indicadas na Tabela 3 abaixo.

Tabela 3 - Classes de solos com suas áreas e respectivas porcentagens na malha da área estudada.

\begin{tabular}{ccc}
\hline Descrição & \multicolumn{2}{c}{ Área } \\
\hline Classificação no 1 $^{\circ}$ nivel Categórico & Hectares & Percentual \\
\hline Plintossolos & 585,77 ha & $54,43 \%$ \\
Plintossolos+Neossolos* $^{*}$ & 226,43 ha & $21,04 \%$ \\
Neossolos & $0,75 \%$ \\
Cambissolos $^{* *}$ & 8,07 ha & $16,05 \%$ \\
Gleissolos & 172,73 ha & $2,14 \%$ \\
Latossolos & 23,03 ha & $1,39 \%$ \\
\hline
\end{tabular}

*Referente a uma malha de transição que se mistura entre os Plintossolos e os Neossolos

${ }^{* *}$ Referente à área com Neossolos foram da malha de transição

A classe dos Plintossolos foi a mais comum, representando $54,43 \%$ da área total da propriedade. A associação de classes que é representada por uma área de transição onde a presença de Plintossolos Pétricos entremeados com Neossolos Regolíticos cobre uma de aproximadamente $21,04 \%$ da comunidade. Ambiente considerado de fragilidade, pois as fragilidades impostas pelos solos associados ao relevo movimentado (íngreme) sugere uma área com riscos de processos degradativos.

A classe dos Cambissolos predominantes representa $16,05 \%$ da área, situado em relevos mais plano/suave ondulado, argila de atividade baixa apresenta algum potencial para o uso agrícola. Ao contrário, podemos analisar que quando esses estão associados a relevos mais declivosos e espessuras mais rasas terão restrições ao uso agrícola.

Os Gleissolos representam 2,14\% da área, apresenta baixa (distróficos) fertilidade natural, é solo considerados mal ou muito mal drenados, em condições naturais, altamente susceptíveis a contaminação. Considerando que a principal atividade da comunidade é a mandioca destinada para fabricação de farinha, o resíduo resultante da prensagem da raiz (manipueira), apresenta elevadas concentrações de glicosídeos cianogênicos, que após decomposição podem formar ácido cianídrico (HCN). Para Zacarias, (2011) o processamento da mandioca, para produção da farinha, resulta na retirada dessa substância tóxica do alimento, e por isso libera HCN como resíduo na natureza. 
INDICAÇÃO DE USO E OCUPAÇÃO DO SOLO DA COMUNIDADE QUILOMBOLA BARRA DO AROEIRA - SANTA TEREZA DO TOCANTINS - TO

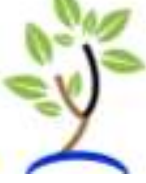

Desta forma, faz-se necessário fazer intervenções acerca da deposição final desse subproduto da mandioca para evitar contaminação dos recursos hídricos, pois a proximidade deles com os rios limita o uso agrícola desta classe de solos, sendo, também, área indicada para preservação das matas ciliares.

A classe dos Latossolos representa $1,39 \%$ da área, devido às boas condições físicas e aos relevos mais suaves, apresentam alto potencial para o uso agrícola. São largamente utilizados com produção na comunidade. São normalmente resistentes aos processos erosivos, devido às boas condições físicas, porém o mau manejo pode ocasionar degradação estrutural e erosão. Na comunidade é o solo mais utilizado para o plantio de milho e mandioca.

E finalmente os Neossolos representam $0,75 \%$ da área em relevo ondulado, associados com processos erosivos em sulcos profundos, principalmente nas estradas rurais (vicinais). Processos erosivos dessa natureza são bastante comum, por não serem pavimentadas, e muitas vezes relegados a segundo plano. Para Grace III (2000), essas estradas carregam e concentram sedimentos, e a magnitude dos efeitos depende principalmente do tipo de solo, declividade, precipitação local. Cunha et al., 2013, concluiu que a grande parte dessas estradas rurais não possuem dissipadores de energia que associado à declividade contribui ainda mais para a formação de enxurrada. Além disso, ressaltam que as estradas geralmente acompanham o fundo de vale, o que não é indicado, uma vez que estas deveriam ser implantadas nos divisores topográficos sempre que possível.

Para controlar é necessário identificar a origem do escoamento e adotar práticas conservacionistas, sendo a primeira delas, desviar o fluxo que está promovendo a erosão. Cunha et al., (2013) indicaram o uso de caixa de contenção para minimizar os efeitos deste tipo de erosão.

Em relação ao seu potencial produtivo, desconsidera-se essa área para uso agrícola, principalmente devido às fragilidades inerentes da própria classe, e, sobretudo devido à posição deles na paisagem associados com relevos ondulados.

De maneira geral, o planejamento de utilização e manejo do solo, deve ser baseado primordialmente em seu potencial produtivo. Sendo que, para manejar o solo de forma adequada, é preciso levar em consideração suas propriedades físicas, químicas e biológicas. Um bom manejo do solo é aquele que proporciona boa produtividade ao mesmo tempo em que possibilita a manutenção de sua saúde, garantindo resiliência e produção agrícola futura.

Observa-se que a área apresenta uma heterogeneidade de classes de solos, cada uma com suas características, potencialidades, fragilidades e formas de manejo gerais. Assim, no momento da escolha de manejo, devem ser assistidas as suas condições, sendo adotadas práticas de manejo respeitando suas particularidades, como indica Azevedo e Bueno (2016).

A fim de mensurar tais diferenças dentro da mesma classificação do solo, a consideração das características físicas, posição no relevo, observação quanto à presença de matéria orgânica, raízes, horizontes impeditivos, hidromorfia, entre outras situações são determinantes na decisão de uso. 
INDICAÇÃO DE USO E OCUPAÇÃO DO SOLO DA COMUNIDADE QUILOMBOLA BARRA DO AROEIRA - SANTA TEREZA DO TOCANTINS - TO

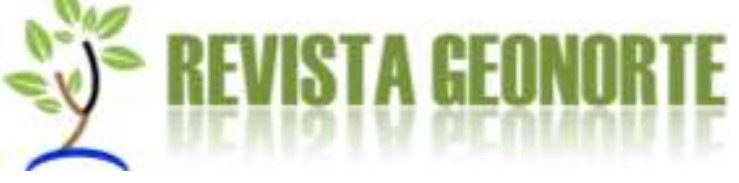

Com a aplicação do sistema de capacidade de uso das terras, chegou-se ao seguinte resultado (Figura 3), após avaliação das características limitantes das unidades de mapeamento do território.

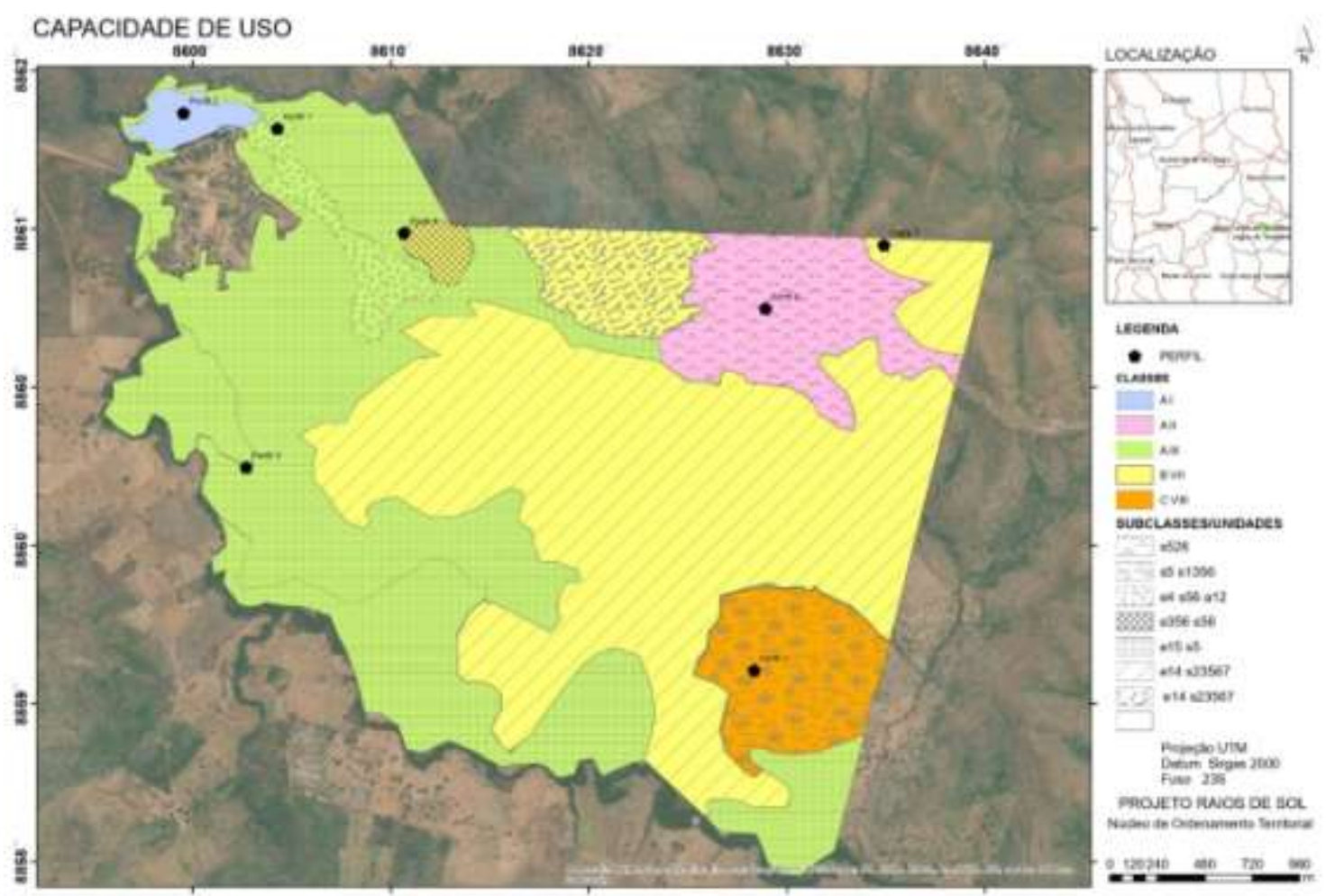

Figura 3 - Mapa de Capacidade de Uso do Solo da área da Comunidade Quilombola Barra da Aroeira - TO.

Os fatores mais limitantes foram relacionados ao solo, problemas com fertilidade química, principalmente toxicidade por alumínio, baixa CTC, textura franca e arenosa. Além disso, foram ressaltados impedimentos físicos, e posteriormente situações que envolviam presença de processos erosivos, desde mais leves, como erosão laminar até os mais severos como erosão em sulcos em relevos acentuados.

Posteriormente quando considerados os critérios do Sistema de aptidão agrícola das terras, o resultado foi bastante semelhante, conforme pode ser verificado na Figura 4. 
INDICAÇÃO DE USO E OCUPAÇÃO DO SOLO DA COMUNIDADE QUILOMBOLA BARRA DO AROEIRA - SANTA TEREZA DO TOCANTINS - TO
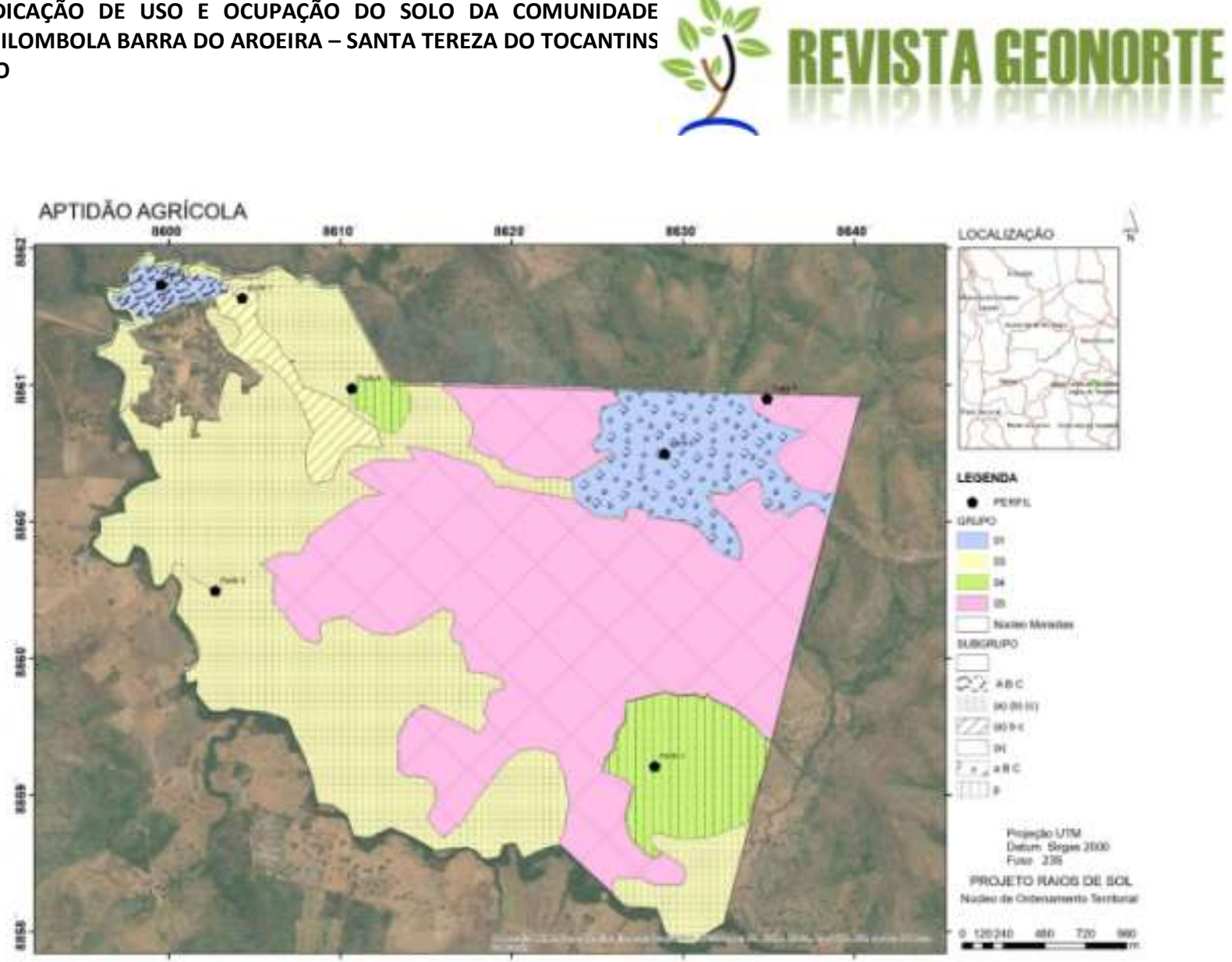

Figura 4 - Mapa de aptidão agrícola do solo da Comunidade Quilombola Barra da Aroeira TO.

Os fatores limitantes mais decisivos para esse sistema foram os impedimentos a mecanização, ocasionado pela presença de solos com concreções superficiais, rasos, e situados em relevos ondulado. A susceptibilidade a erosão também foi bastante ressaltada, considerando além de solos de alta erodibilidade associados a chuvas erosivas comum no Estado do Tocantins, não devendo esquecer que, além disso, a estacionalidade climática é um fator decisivo no cultivo destas terras. Assim como no sistema de capacidade de uso, o quesito fertilidade foi bastante ressaltado, classificando a maior parte dos solos como muito alta para deficiência a fertilidade.

Como foi visto, existem áreas que estão aptas para atividades agrícolas e outras não. Essas áreas que dispõem de melhores condições, podem ser utilizadas para cultivos mais intensivos, por apresentar maior exigência em relação a profundidade do solo, relevo mais plano, qualidades químicas e físicas, entre outras situações. Os moradores da comunidade querem implantar uma casa de farinha, sendo, portanto, necessário indicar uma área para o cultivo da mandioca. Outra necessidade deles é a implantação de sistemas integrados de culturas anuais com fruticultura. Essas seriam as indicações para as áreas mais aptas.

$\mathrm{Na}$ área de Cambissolo Flúvico não se recomenda criação de animais. Atualmente é a atividade que predomina nesse local, porém a indicação é fazer a retirada do gado, pois se trata de um ambiente que sofre oscilações do lençol freático, a 
INDICAÇÃO DE USO E OCUPAÇÃO DO SOLO DA COMUNIDADE QUILOMBOLA BARRA DO AROEIRA - SANTA TEREZA DO TOCANTINS - TO

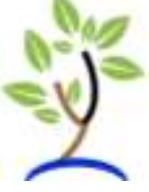

permanência dos animais neste local acarretaria além de processos erosivos, contaminação da água por dejetos de animais. Em relação às outras criações, os mesmos cuidados devem ser tomados, pois criação de suínos bem como de galináceos geram resíduos que devem ser destinados de forma correta, ou mesmo reutilizado em forma de adubo para nas plantações de hortaliças.

A área amarela seria destinada à pecuária extensiva, tanto pela adaptação das pastagens a diversas condições de solo e relevo, quando à rusticidade dos animais, além de não haver empecilhos pedológicos. Essa mesma área também pode ser indicada ao cultivo de florestas plantadas, estando em pauta à instalação de um sistema agroflorestal pela comunidade, assim como cordões verdes de isolamento, servindo também para a demarcação do território, que constantemente sofre invasão dos moradores vizinhos.

Já a parte em rosa na Figura 4, devido ao difícil acesso, pode-se indicar essas áreas para preservação permanente, considerando características como, forte presença de plintitas e petroplintitas, fragmentos de rocha, solos rasos, afloramentos de rochas e relevos íngremes, sendo exigida a não antropização também pela fragilidade desses locais.

O percentual da área que foi indicada para não ter uso ultrapassa o mínimo exigido para o Bioma cerrado, que é de $35 \%$, englobando Áreas de Preservação Permanente (APP) e de Reserva Legal (RL), de acordo com a Lei $N^{\circ} 12.651$, DE 25 DE MAIO DE 2012 (BRASIL, 2012). Em suma, na comunidade a área destinada para uso intensivo agrícola é de 128,79 ha, para uso pecuário e plantações florestais é de 464,75 ha, e finalmente para preservação de fauna e flora é de 472,25 ha. A área destinada para a construção de moradias (área urbana) não foi considerada. Assim todo o território possui o total de 1076,17 ha.

A maior fração da área indicada para preservação ambiental implica em uma menor área para utilização e exploração agrícola ou pecuária. Contudo, vale ressaltar que nessa área pode-se fazer o uso extrativista de sementes, cascas, folhas para atividades artesanais. Considerando, que a comunidade está localizada na rota turística do Jalapão, é possível explorar esse mercado, oferecendo produtos de fabricação própria artesanal, desde bijuterias até alimentos em conserva.

\section{CONCLUSÃO}

Apenas $12 \%$ da área, ou seja, 128,79 ha são indicados para o uso agrícola. Fatores como baixa fertilidade natural, susceptibilidade a erosão, relevo íngreme, solos rasos e/ou com impedimentos físicos foram as principais fragilidades encontradas na área. O baixo nível tecnológico dos agricultores imprime impedimentos para um uso mais intensivo das terras. $44 \%$ da área não apresenta aptidão para uso, sendo destinada para preservação ambiental.

\section{REFERÊNCIAS}


INDICAÇÃO DE USO E OCUPAÇÃO DO SOLO DA COMUNIDADE QUILOMBOLA BARRA DO AROEIRA - SANTA TEREZA DO TOCANTINS - TO

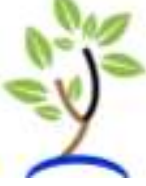

ALTIERI, M.; FUNES-MONZOTTE, F.; PETERSEN, P. Agroecologically eficiente agricultural systems for smallholder farmers: contributions to food sovereignty. Agronomy for Sustainable Development, v. 32, p. 1-13, 2012.

AZEVEDO, J. R.; BUENO, C. R. P. Potencialidades e limitações agrícolas de solos em assentamento de reforma agrária no município de Chapadinha-MA. Curitiba PR. Revista Scientia Agraria v. 17 n. 3, p. 1-13, 2016.

BENNEMA, J.; BEEK, K. J.; CAMARGO, M. N. Um sistema de classificação de capacidade de uso da terra para levantamentos de reconhecimento de solos. Rio de Janeiro: Ministério da Agricultura, Divisão de Pedologia e Fertilidade do Solo, 1965. $50 p$.

BRASIL. Lei $n^{\circ}$ 12.651, de 25 de maio de 2012 - Institui o novo código florestal brasileiro. 2012. Disponível em: <http://www.planalto.gov.br/ccivil 03/ ato20112014/2012/lei/l12651.htm>. Aceso em: 27 nov. 2020.

CUNHA, M. C.; THOMAZ, E. L.; VESTENA, L. R. Medidas de controle de erosão em estradas rurais na bacia do rio das pedras, Guarapuava-PR. Sociedade \& Natureza. Uberlândia - MG, v.25, n. 1, p.107-118, 2013.

EMBRAPA. Centro Nacional de Pesquisa de Solos (Rio de Janeiro. RJ). Procedimentos normativos de levantamentos pedológicos - Brasília: EMBRAPA SPI. 1995.

EMBRAPA. Centro Nacional de Pesquisa de Solos. Manual de métodos de análise de solos. 3 ed. rev. Rio de Janeiro: EMBRAPA, 2017. 573p.

EMBRAPA - Sistema Brasileiro de Classificação de Solos. 5. ed., rev. e ampl. Brasília, DF : Embrapa, 2018. 356 p.

FCP. Fundação Cultural Palmares. Certificação Quilombola. Disponível em: http://www.palmares.gov.br/?page id=37551. Acesso em: 11 de nov. 2020. 
INDICAÇÃO DE USO E OCUPAÇÃO DO SOLO DA COMUNIDADE QUILOMBOLA BARRA DO AROEIRA - SANTA TEREZA DO TOCANTINS - TO

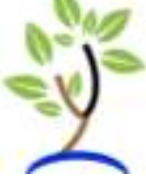

FRANÇA, B. B.; LIMA, J. J. M.; SOUSA, K. A.; ARAÚJO, L. F.; SANTOS, M. A.; CARMO, S. S.; RAMOS, M. R. Capacidade de uso e aptidão agrícola de uma fazenda em São Domingos do Araguaia (PA). Revista Geonorte, v.10, n.35, p.153167, 2019.

GRACE III, J. M. Forest road sideslopes and soil conservation techniques. Journal of Soil and Water Conservation, Ankeny, v. 55, p.1-9, 2000.

LEPSCH, I. F. Manual para levantamento utilitário do meio físico e classificação de terras no sistema de capacidade de uso. Campinas: SBCS, 1991. 175p.

MARIN, R. E. A.; ALMEIDA, A. W. Populações Tradicionais: Questões de terra na Pan-Amazônia. Belém: Associação de Universidades Amazônicas, 2006. 104p.

NIEDERLE, MURIEL, CARMIT SEGAL, AND LISE VESTERLUND, "How Costly is Diversity? Affirmative Action in Light of Gender Differences in Competitiveness". Management Science, v. 59, n. 1, p. 1-16, 2013.

RAMALHO FILHO, A.; BEEK, K. J. Sistema de avaliação da aptidão agrícola das terras. 3.ed. Rio de Janeiro: EMBRAPA, 1995. 65p.

PINTO, A.R; BORGES, J.C.; NOVO, M.P.; PIRES, P.S. Quilombos do Brasil: segurança alimentar e nutricional em territórios titulados. Cadernos de Estudos Desenvolvimento Social em Debate. $n^{\circ} 20,2014$. ISSN 1808-0758.

SOUZA, D. M. G.; LOBATO, E. Cerrado: uso correção do solo e adubação. 2. Ed. Brasilia, DF: Embrapa Informação Tecnológica 2004. 416 p.

ZACARIAS, C. H. Avaliação da exposição de trabalhadores de casas-de-farinha ao ácido cianídrico proveniente da mandioca, Manihot esculenta, Crantz, no agreste alagoano. 2011. Dissertação (Mestrado em Toxicologia e Análises Toxicológicas) Faculdade de Ciências Farmacêuticas - Universidade de São Paulo (USP). 147 f. 2011. 